\title{
Tuberculosis Miliary in Patients Treated With Bacillus Calmette-Guerin Immunotherapy: Case Report
}

\author{
Marta Batista $^{\mathrm{a}, \mathrm{c}}$, Carlos Alves ${ }^{\mathrm{b}}$, Carlos Boinas $^{\mathrm{b}}$, Elvira Camacho $^{\mathrm{b}}$
}

\begin{abstract}
Bacillus Calmette-Guerin (BCG), a live attenuated form of Mycobacterium bovis (M. bovis), is the most effective intravesical agent in the treatment of non-invasive bladder cancer. This therapy can cause minor complications like urinary frequency, fever, dysuria and hematuria, but it can also cause more serious systemic complications such as hepatitis, pneumonitis and sepsis. Miliary tuberculosis is a very rare complication of BCG immunotherapy and is associated to high mortality, thus this diagnosis must be early considered and early treatment should be implemented. The authors report a case of miliary tuberculosis after treatment with intravesical BCG, with isolation of M. bovis. The patient presented clinical and imaging improvement after initiation of tuberculostatic agents.
\end{abstract}

Keywords: Miliary tuberculosis; Mycobacterium bovis

\section{Introduction}

Bladder cancer is the ninth most frequent neoplasia worldwide [1], with $70 \%$ of new cases being non-invasive [2]. Several studies have shown that the risk of progression and recurrence of non-invasive bladder neoplasia with bacillus CalmetteGuerin (BCG) is lower than with other intravesical chemotherapies such as mitomycin, epirubicin and gemcitabine [3, 4]. Thus American and European Urology Associations recommend the use of intravesical BCG in the treatment of noninvasive cancer for all patients at high risk of disease progression and for selected intermediate risk patients $[5,6]$.

The mechanism of action of BCG is not fully understood; however, several immunological changes are reported that appear to contribute to its antitumor activity, notably by local increase in CD4 T lymphocytes and macrophages, interleukin-1 (IL-1), IL-2, IL-6, IL-8, IL-12, tumor necrosis factor alpha and

Manuscript submitted June 14, 2017, accepted June 26, 2017

ammunoallergology Department, Hospital Sao Bernardo Setubal, Portugal bPneumology Department, Centro Hospitalar Barreiro Montijo, Portugal ${ }^{\mathrm{c} C}$ Corresponding Author: Marta Martins Batista, Servico de Imunoalergologia, Hospital de Sao Bernardo, Rua Camilo Castelo Branco, 2910-446 Setubal, Portugal.Email: marttamarttins@gmail.com

doi: https://doi.org/10.14740/jmc2862w interferon-gamma $[7,8]$. This is a very effective immunotherapy since the bladder being a closed compartment allows high local concentrations of BCG and consequently an effective and long lasting recruitment of the immune cells.

Complications of intravesical BCG therapy include local and systemic reactions. Shelley et al [9], in a review that included six randomized trials, found that the toxicities most frequently associated with this therapy were urinary frequency $(71 \%)$, cystitis $(67 \%)$, fever $(25 \%)$ and hematuria $(23 \%)$. In another study involving 2,602 patients, the following systemic complications were observed: high fever $>39.5{ }^{\circ} \mathrm{C}(2.9 \%)$, hematuria $(1.0 \%)$, granulomatous prostatitis $(0.9 \%)$, hepatitis or granulomatous pneumonitis $(0.7 \%)$, arthralgia $(0.5 \%)$, epididymitis $(0.4 \%)$, sepsis $(0.4 \%)$, rash $(0.3 \%)$, ureteral obstruction $(0.3 \%)$, bladder contracture $(0.2 \%)$, renal abscess $(0.1 \%)$ and cytopenia $(0.1 \%)$ [10]. In a more recent review that included a total of 282 patients with complications, the authors found more frequent disseminated disease $(34.4 \%)$, genitourinary infections $(23.4 \%)$ and musculoskeletal infections $(19.9 \%)$ [11].

In this article, we describe a rare case of miliary tuberculosis with isolation of Mycobacterium bovis (M. bovis) in the urine as a complication of intravesical BCG treatment.

\section{Case Report}

The patient was a 53-year-old caucasian male with no relevant personal history beyond the diagnosis of non-invasive stage I bladder carcinoma. He underwent transurethral tumor resection and initiated intravesical BCG instillations 1 month after surgery. He performed a total of seven intravesical instillations which were done monthly, without any registered intercurrence. Three weeks after the last instillation, the patient started with unproductive cough, fever (maximum registered $39^{\circ} \mathrm{C}$ ) and sweating. He went to the hospital Emergency Department and was hospitalized. At admission, the patient had a normal physical examination, except for the temperature of $38.5^{\circ} \mathrm{C}$ and heart rate of 90 beats per minute. Pulmonary auscultation revealed a slightly diminished vesicular murmur, with no adventitious sounds. The patient denied dyspnoea, thoracalgia, expectoration and hemoptyses. The following laboratory alterations were found: erythrocytes $4.4 \times 10^{6} \mu \mathrm{L}$, hemoglobin $11.6 \mathrm{~g} / \mathrm{dL}$, mean globular volume $82 \mathrm{fL}$, urea $17 \mathrm{mg} / \mathrm{dL}$, creatinine $0.66 \mathrm{mg} / \mathrm{dL}$, sodium $134 \mathrm{mEq} / \mathrm{L}$, gamma glutamyltransferase $133 \mathrm{IU} / \mathrm{L}$, aspartate aminotransferase $59 \mathrm{IU} / \mathrm{L}$, and C-reactive protein (CRP) 


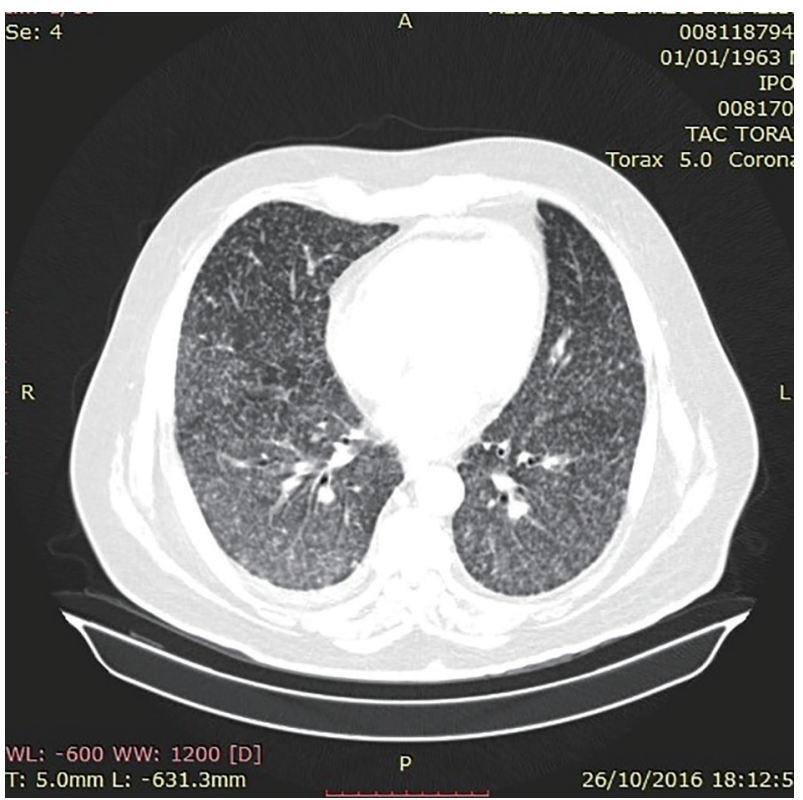

Figure 1. Thorax computed tomography revealing small, diffuse and bilateral pulmonary nodules suggestive of miliary tuberculosis.

$4.19 \mathrm{mg} / \mathrm{dL}$. The chest X-ray performed at admission showed no pathological changes. The patient performed blood, sputum and urine collection for bacteriological and mycological examination. Empirical antibiotic therapy with meropenem was initiated. During the first days of hospitalization, the patient maintained daily high fever peaks and his clinical condition worsened. Therefore, the diagnosis of disseminated BCG infection was considered and tuberculostatic therapy was started on the eighth day with isoniazid, pyrazinamide, ethambutol and rifampicin. After the institution of the quadruple antibacte-

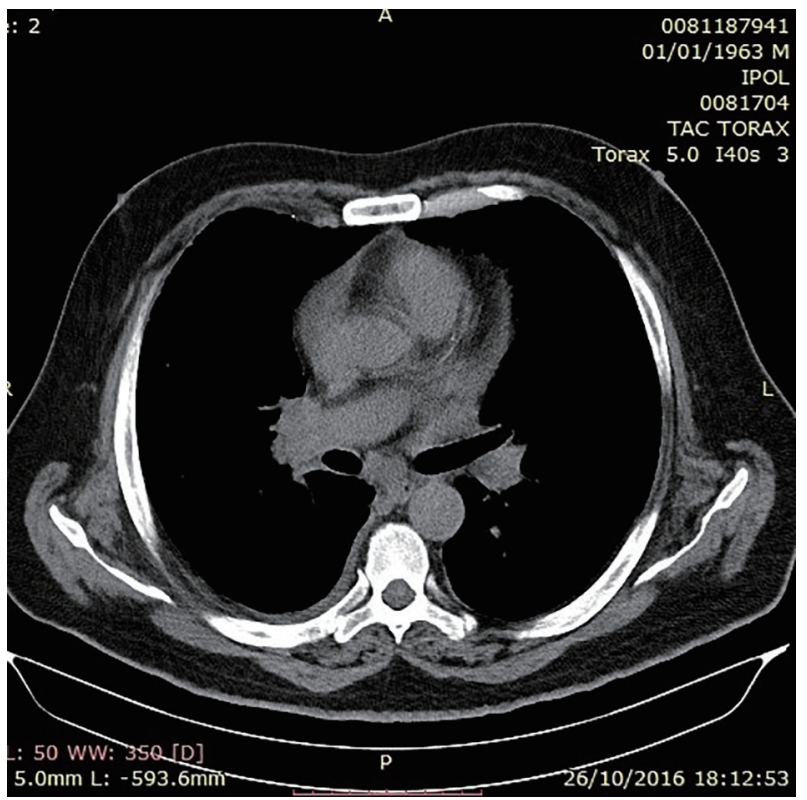

Figure 2. Thorax computed tomography revealing mediastinal adenomegalies in right superior paratracheal topography and infracarinal.

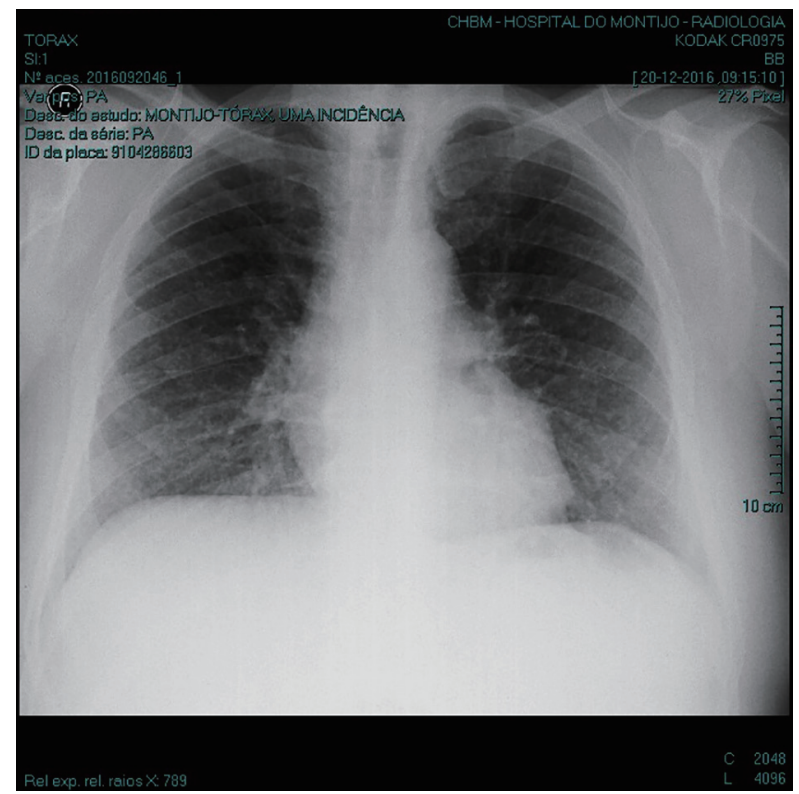

Figure 3. Chest $\mathrm{X}$-ray with bilateral miliary interstitial pattern.

rial therapy, the patient presented improvement of symptoms, with apirexia and decreased cough. On the 13th day of hospitalization, computed tomography of the thorax was performed, which revealed multiple small and diffuse pulmonary nodules, with a predominant centrilobular distribution suggesting miliary tuberculosis (Fig. 1). There were also mediastinal adenomegalies (Fig. 2). At the 16th day of hospitalization, the patient performed bronchofibroscopy without evidence of bacilli in the bronchoalveolar lavage and secretions. Three weeks after the onset of symptoms, chest X-ray presented a generalized reticulo nodular pattern compatible with miliary tuberculosis (Fig. 3). During hospitalization, the patient presented progressive improvement of liver function tests and normalization of CRP. The patient was discharged after 8 days of apirexia and was followed in an outpatient Pneumology Department. Blood cultures, sputum and bronchoalveolar lavage were negative. $M$. bovis was isolated in the urine and its antibiogram revealed resistance to pyrazinamide. Therefore, the patient started to perform triple antibacterial therapy, mantained for 2 months, followed by double therapy with isoniazid and rifampicin. He is currently in the fourth month of treatment, does not present any alterations in physical examination and remains asymptomatic.

\section{Discussion}

The clinical presentation of disseminated disease in patients who develop a miliary imaging pattern can be varied, with patients being relatively asymptomatic [12], patients with flulike complaints, and others with a rapid progression to sepsis, respiratory failure and sometimes death $[13,14]$. In addition, as it has been observed in our patient, the diagnosis is often delayed by the fact that the thorax radiography has a low sensitivity, not allowing the diagnosis in many cases with a disseminated miliary pattern later proven in CT [11]. Sometimes 
the definitive diagnosis is difficult because it is not possible to isolate $M$. bovis nor to identify its DNA, although non-caseous granulomas are in many cases found in lung biopsies. An explanation presented in the literature relates to a cross-reaction between the autoantigens and the antigens of the mycobacteria, so a hypersensitivity response is considered being responsible for the disseminated disease. A relevant feature in the present case is the isolation of $M$. bovis in urine, an aspect in favor of the hypothesis of hematogenous dissemination of mycobacteria as a mechanism to explain the systemic complication. The recommended treatment is triple antibiotic therapy (isoniazid, rifampicin and etambutol) for 2 months followed by double therapy (isoniazid and rifampicin) for 4 months [11]. It should be noted that although $M$. bovis is intrinsically resistant to pyrazinamide [15], several cases have been described in which it was included in the treatment of these patients with no apparent impact on therapeutic success [11]. Our patient showed a rapid improvement in his clinical symptoms right after the start of the quadruple antibacterial therapy.

Although there are some risk factors described in the literature (immunocompromised state, hematological malignancy, pregnant women or breast-feeding women) [10], there are no predictors of disseminated disease following intravesical BCG therapy. Thus a high level of suspicion is required in patients submitted to this therapy and who develop moderate to severe local symptoms or even systemic symptoms without apparent cause. Delaying the tuberculostatic therapy can aggravate the prognosis of miliary tuberculosis, therefore this diagnosis should be considered when evaluating this kind of clinical presentation.

\section{Conflicts of Interest}

The authors declare no conflicts of interest related to this manuscript.

\section{References}

1. Elkabani M, Greene JN, Vincent AL, VanHook S, Sandin RL. Disseminated Mycobacterium bovis after intravesicular bacillus calmette-Gu rin treatments for bladder cancer. Cancer Control. 2000;7(5):476-481.

2. Antoni S, Ferlay J, Soerjomataram I, Znaor A, Jemal A, Bray F. Bladder cancer incidence and mortality: a global overview and recent trends. Eur Urol. 2017;71(1):96-108.

3. Sylvester RJ, van der Meijden AP, Witjes JA, Kurth K. Bacillus calmette-guerin versus chemotherapy for the intravesical treatment of patients with carcinoma in situ of the bladder: a meta-analysis of the published results of randomized clinical trials. J Urol. 2005;174(1):86-91; discussion 91-82.

4. de Reijke TM, Kurth KH, Sylvester RJ, Hall RR, Brausi
M, van de Beek K, Landsoght KE, et al. Bacillus Calmette-Guerin versus epirubicin for primary, secondary or concurrent carcinoma in situ of the bladder: results of a European Organization for the Research and Treatment of Cancer - Genito-Urinary Group Phase III Trial (30906). J Urol. 2005;173(2):405-409.

5. Babjuk M, Bohle A, Burger M, Capoun O, Cohen D, Comperat EM, Hernandez V, et al. EAU Guidelines on Non-Muscle-invasive Urothelial Carcinoma of the Bladder: Update 2016. Eur Urol. 2017;71(3):447-461.

6. Kassouf W, Traboulsi SL, Kulkarni GS, Breau RH, Zlotta A, Fairey A, So A, et al. CUA guidelines on the management of non-muscle invasive bladder cancer. Can Urol Assoc J. 2015;9(9-10):E690-704.

7. Bohle A, Brandau S. Immune mechanisms in bacillus Calmette-Guerin immunotherapy for superficial bladder cancer. J Urol. 2003;170(3):964-969.

8. Prescott S, Jackson AM, Hawkyard SJ, Alexandroff AB, James K. Mechanisms of action of intravesical bacille Calmette-Guerin: local immune mechanisms. Clin Infect Dis. 2000;31(Suppl 3):S91-93.

9. Shelley MD, Court JB, Kynaston H, Wilt TJ, Coles B, Mason M. Intravesical bacillus Calmette-Guerin versus mitomycin $\mathrm{C}$ for Ta and T1 bladder cancer. Cochrane Database Syst Rev. 2003;3:CD003231.

10. Lamm DL, van der Meijden PM, Morales A, Brosman SA, Catalona WJ, Herr HW, Soloway MS, et al. Incidence and treatment of complications of bacillus Calmette-Guerin intravesical therapy in superficial bladder cancer. J Urol. 1992;147(3):596-600.

11. Perez-Jacoiste Asin MA, Fernandez-Ruiz M, LopezMedrano F, Lumbreras C, Tejido A, San Juan R, Arrebola-Pajares A, et al. Bacillus Calmette-Guerin (BCG) infection following intravesical BCG administration as adjunctive therapy for bladder cancer: incidence, risk factors, and outcome in a single-institution series and review of the literature. Medicine (Baltimore). 2014;93(17):236254.

12. Choi CH, Lee SO, Smith G. Subclinical miliary Mycobacterium bovis following BCG immunotherapy for transitional cell carcinoma of the bladder. BMJ Case Rep. 2014;2014.

13. Del Castillo Duran Y, Santos Bodi F, Castander Serentill D, Jubert Montaperto P, Espinosa Valencia P, Rabasso Sole C. [Tuberculosis miliar in a patient treated with intravesical instillations of bacillus Calmette-Guerin]. Med Intensiva. 2006;30(3):116-119.

14. Viallard JF, Denis D, Texier-Maugein J, Parrens M, Faure I, Pellegrin JL, Leng B. Disseminated infection after bacille Calmette-Guerin instillation for treatment of bladder carcinoma. Clin Infect Dis. 1999;29(2):451-452.

15. Durek C, Rusch-Gerdes S, Jocham D, Bohle A. Sensitivity of BCG to modern antibiotics. Eur Urol. 2000;37(Suppl 1):21-25. 